\title{
Application of insect songs in monitoring population density level of Locusta migratoria migratoria (Orthoptera: Acrididae)
}

\author{
Yinliang Wang ${ }^{1}$, Qiuchen Huang ${ }^{2}$, Xue Zhang ${ }^{1}$ and Bingzhong Ren ${ }^{1 *}$
}

\begin{abstract}
Background: The locusts Locusta migratoria migratoria (Orthoptera: Acrididae) is the most destructive agricultural pests worldwide, the population and distribution of L. migratoria migratoria growing rapidly in recent years. It is crucial to find a green, economical way to monitor this insect's population for effective control tactics. In this study, acoustic samples were recorded and analyzed under three different density levels of Asian migratory locust $L$. migratoria migratoria.

Results: The results showed that the songs of L. migratoria migratoria had a very stable acoustic feature in time domains; then, we used duration of pulse as a tool for identifying and counting the numbers of pulse to classify the population size. After removing the background noises, an automatic density classification and monitoring system was established based on the backpropagation (BP) neural network. The field sample test showed that the accuracy of the density level recognition reached $96.67 \%$.

Conclusions: The results indicated that the calling songs of insects could be an effective character to distinguish population density level of locust plagues, and it could be potentially used as a green and environmental protection solution in monitoring the dynamics of locust plagues and other acoustic agriculture pests.
\end{abstract}

Keywords: Insect song; Asian migratory locust; Monitoring system

\section{Background}

The various subspecies of migratory locusts such as Locusta migratoria migratoria (Orthoptera: Acrididae) is the most destructive agricultural pests worldwide. In recent years, the areas damaged by L. migratoria migratoria have enlarged geographically in China (Ma et al. 2005; Zhang et al. 2009), and it has caused billions of dollars in property damage. Thus, knowing the dynamics of pest populations is crucial in determining effective control tactics, when to initiate the tactics, and the tactics, once implemented, are successful. Knowing how a population changes could also give us a better understanding of occurrence regularity of the species studied. The current monitoring methods for such species mainly depend on field observations and remote sensing data (Drake et al.

\footnotetext{
* Correspondence: bzren@163.com

'Jilin Key Laboratory of Animal Resource Conservation and Utilization, School of Life Sciences, Northeast Normal University, Renmin St. 5268, Changchun 130024, China

Full list of author information is available at the end of the article
}

2002; Ceccato et al. 2006; Shi et al. 2003). However, due to the high cost of radar and satellite sensor-based monitoring system, it is meaningful to find an effective and economical solution. The application of acoustic signals in monitoring pest populations has inherent advantages: It only needs some acoustic sensors set in the field with connection to a computer which is already programmed, and it is more economic than the satellite sensor-based monitoring system. Moreover, we are willing to establish a system that can automatically calculate the classification results without manual observations. Finally, the application of acoustic signals is also a pollution-free and environment-friendly method compared with some chemical methods such as pheromone traps.

Sound productions have great significance for intraspecific communication, such as interaction and courtship (Ragge and Reynolds 1998), disturbance (García et al. 2003), and performance in a chorus (Ewing 1989). Most insects of Cicadidae and Orthoptera can make sounds, but the methods used to emit sounds are very 
diverse (Uvarov 1996). The femoro-elytral method is the most widespread in suborder Caelifera, producing stridulation by rubbing the posterior femora against the tegmina (Schmidt and Stelzer 2005). Other reports claimed, however, that some apterous grasshoppers developed their own methods to produce sounds (López et al. 2007). The calling songs have a good specificity and steadiness that can be used as an effective indicator in species identification and evolutionary studies (Ngo and Ngo 2013; Wang et al. 2011; Hemp and Kehl 2010; Montealegre-Z and Morris 2004; Pace et al. 2010). For more than several decades, researchers had used sounds produced by insects to detect their presence (Riede 1998; Parkman et al. 1996); in contrast, few attempts have been made to estimate population size and density. There is only one report about monitoring locust density based on some acoustic characters such as diurnal song activity, the song quality, and the audible distance, but this study is mainly focus on some ecological characters (Fischer et al. 1997). Until now, there are no reports of precasting insect densities base on their intraspecies acoustic characters, especially in automatic identifications on a particular species.

In order to test whether the intraspecies acoustic characters could be used to estimate the population density of a particular species, the calling samples of L. migratoria migratoria in three different density levels were recorded and analyzed, and then an automatic density classification and monitoring system was established based on the backpropagation (BP) neural network. The results showed that insect songs could be potentially used as an effective and green method in monitoring locust plagues.

\section{Methods}

\section{Insects}

We used fourth instar larvae of L. migratoria migratoria as specimen, which were collected in Haituo $\left(45^{\circ} 23^{\prime} \mathrm{N}\right.$, $129^{\circ} 9^{\prime} \mathrm{E}, 133 \mathrm{~m}$ in altitude), Da'an, Jilin province, Northeast China. The grassland in Haituo is covered with reeds over 500 ha, and nearly $60 \%$ was attacked by the Asian migratory locust. Gregarious nymphs were raised to adults in the lab, fed with fresh reed leaves, and kept in transparent containers $(55 \mathrm{~cm} \times 53 \mathrm{~cm} \times 50 \mathrm{~cm})$ at $30 \pm 2^{\circ} \mathrm{C}$ with a 12:12-h light-dark cycle. The male/female ratio is nearly $1: 1$ per cage. The life cycle of $L$. migratoria migratoria in this place was also studied by field observation, and the records of the local government were checked. For that, only sexual maturity locust could make songs, and it was important to decide the proper time to monitor the density using this system.

\section{Song recording and analysis}

The experiment was divided into three groups, which were defined with actual locust infestation during the past several years according to the local government's records: slight locust plagues, 5 individuals per box $\left(0.5 \mathrm{~m}^{3}\right)$; moderate locust plagues, 25 individuals per box $\left(0.5 \mathrm{~m}^{3}\right)$; and heavy locust plagues, 50 individuals per box $\left(0.5 \mathrm{~m}^{3}\right)$. Within 2 months of collection, we recorded the calling songs of both males and females in our lab as sound files using a digital voice recorder (PCM-D50 Digital Recorder, Sony Corporation, Tokyo, Japan). The sampling rate was $96 \mathrm{kHz}$, and the recorder was placed in the center of the box. It was reported that the acoustic behaviors and the traits of songs changed with temperature (von Helversen 1972), so the temperature was taken under natural sunlight during recording. Each recording sample took $1 \mathrm{~h}$, which was divided into six 10-min samples; each density got 30 samples, and thus, a total of 90 samples were obtained. Thereinto, 45 samples were used as training samples to train the BP neural network, and the remaining 45 samples were used as testing samples to test the system we built. The width of the pulses, the intervals between pulses and pulses groups, the normalized amplitude of pulses, and the amplitude ratio between pulses were analyzed using Cool Edit (Cool Edit pro V2.1, Adobe Systems) and Matlab (Matlab 7.0, Mathworks) with at least 16 different individuals.

\section{BP neural network}

For the purpose of automatically classifying and monitoring the population density of $L$. migratoria migratoria pest, we used the backpropagation neural network. Standard backpropagation is a gradient descent algorithm, as is the Widrow-Hoff learning rule, in which the network weights are moved along the negative of the gradient of the performance function. The term 'backpropagation' refers to the manner in which the gradient is computed for nonlinear multilayer networks. There are a number of variations on the basic algorithm that are based on other standard optimization techniques, such as conjugate gradient and Newton methods.

We used three independent layers: input, hidden, and output layers. As for our purpose, after removing the background noise, the number of efficient pulses was used as input layers, and three different density levels were used as output layers. The number of input neurons depends on the dimension of input vector; in this text, the dimension of input vector was threedimensional, so we used three neurons in input layers. The number of neurons in output layers was three; it was based on the three density levels of locust pest we mentioned above. The number of neurons in hidden layers was determined by the formula $n=\sqrt{n_{\mathrm{i}}+n_{\mathrm{o}}}+a$, where $n$ was the number of neurons in hidden layers, $n_{\mathrm{i}}$ was the number of neurons in input layers, $n_{\mathrm{o}}$ was the number of neurons in output layers, and $a$ was a constant between 1 and 10 (we took 5 here, which was 


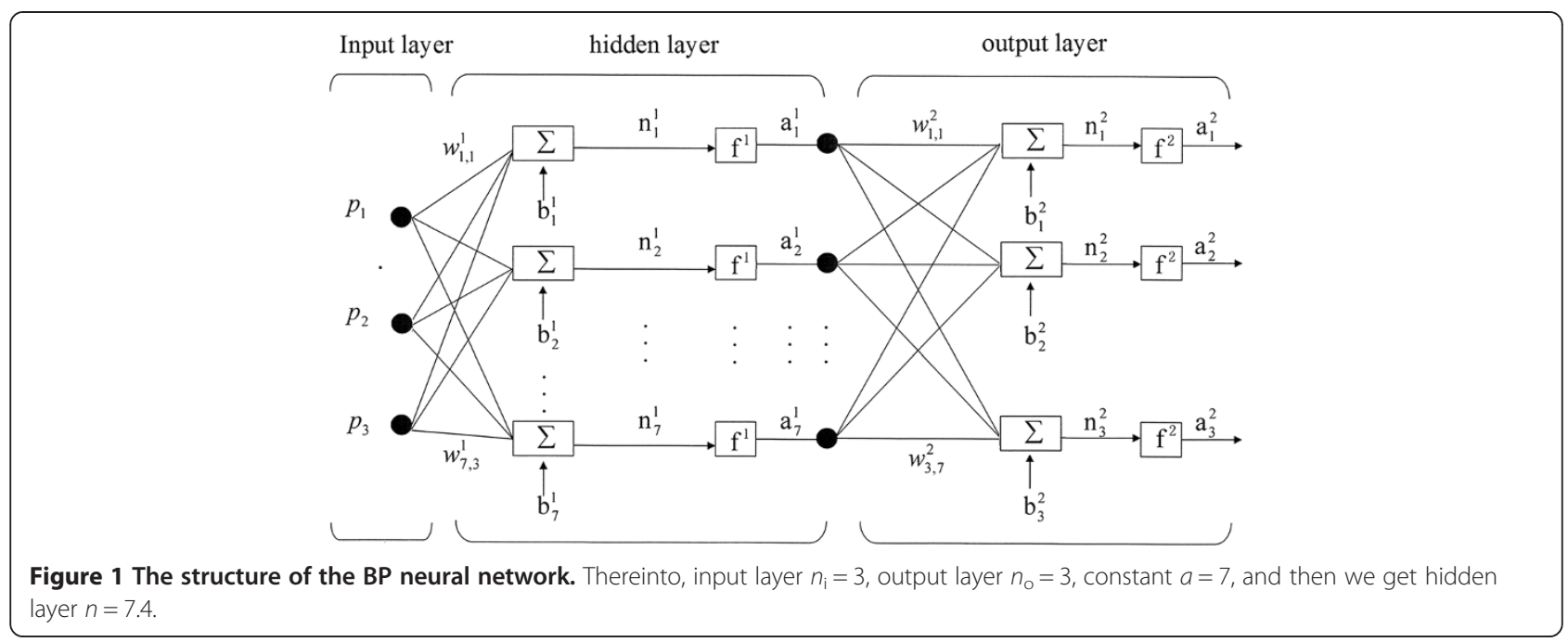

an intermediate value). Finally, we got $n=7.4$, so we used seven neurons in hidden layers. The structure of the BP neural network that we used is shown in Figure 1.

\section{Data preprocessing}

Background noise can be divided into stationary noise and impulse noise. The former can be conveniently removed by setting a proper threshold and clamping it. We set the normalized threshold as 0.1 (this threshold is based on the signal to noise $(\mathrm{S} / \mathrm{N})$ ratio); the latter cannot be removed by clamping because its amplitude of shortwave is similar to that of locust songs. Therefore, we converted the migratory locust songs and impulse noise into Bohr square wave after removing the stationary noise (Figure 2a,b,c). No overlapping pulses were mainly distributed between threshold 0.1 and 0.7 . As will be mentioned in the 'Results' section, the calling songs of L. migratoria migratoria have an obvious character of double pulses, and the average width values of pulse A and pulse B were 15.45 and 17.74 ms, respectively (Table 1). In actual situations, most of the impulse noise differs greatly from locust songs in the width of pulse. The impulse noise would not be counted by cutting off the bad data. The impulse noises, which had the same width as locust songs in minor cases, should exert no effect on the statistical result.

When the population density is very high, there maybe some overlapping pulses; when it occurs, it will not only increase the amplitude but also will prolong the durations of the pulses. To identify this situation, there are two
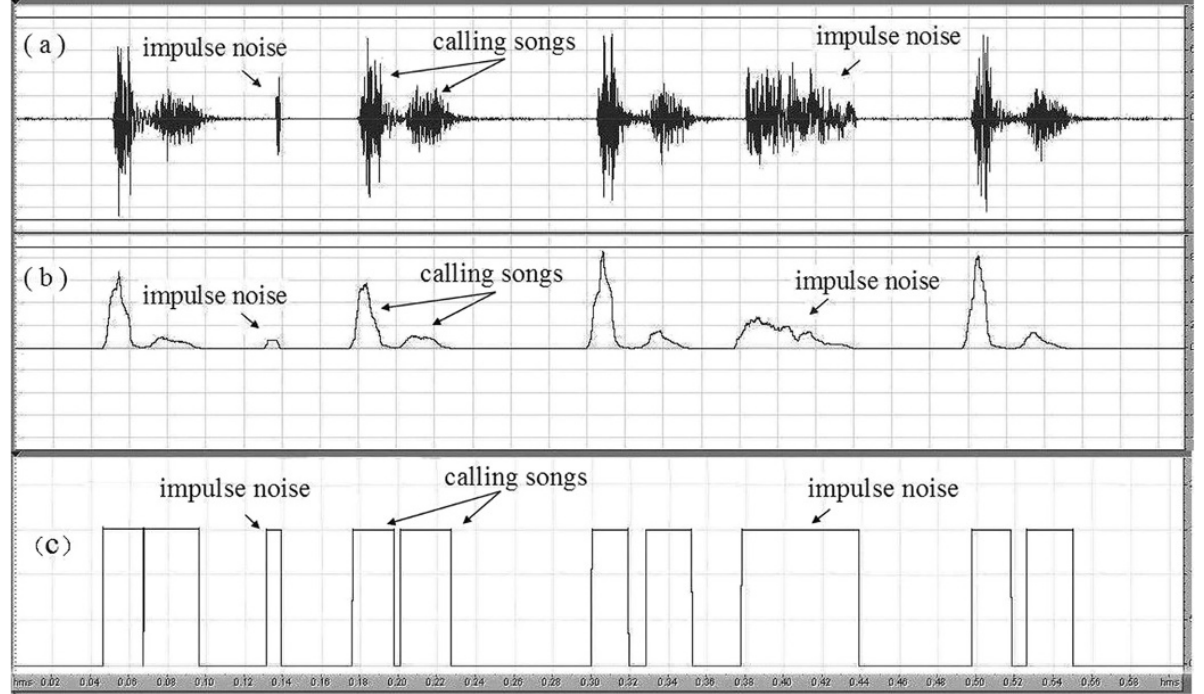

Figure 2 Locusta migratoria migratoria calling songs with impulse noise. (a) The time domain plot of Locusta migratoria migratoria songs and impulse noise. (b) The corresponding short-time energy diagram. (c) The corresponding Bohr square waveform. 
Table 1 Time domain song traits of $L$. migratoria migratoria

\begin{tabular}{lllll}
\hline & Number of samples & Average & Standard error & Relative error (\%) \\
\hline Width of pulse A (ms) & 187 & 15.45 & 0.25 & 1.7 \\
Width of pulse B (ms) & 187 & 17.74 & 0.36 & 2.1 \\
Intervals between A and B (ms) & 186 & 7.49 & 0.36 & 4.9 \\
Intervals between double pulses (ms) & 186 & 73.1 & 1.5 & 2.1 \\
Amplitude of pulse A (normalized) & 187 & 0.293 & 0.019 & 6.3 \\
Amplitude of pulse B (normalized) & 187 & 0.0736 & 0.0036 & 4.9 \\
Amplitude ratio A/B & 187 & 4.12 & 0.25 & 6.0 \\
\hline
\end{tabular}

symbols: firstly, the amplitude was over the normalized threshold 0.7; secondly, the duration of pulse A is between 15.45 and $30.90 \mathrm{~ms}$, and pulse B is between 17.74 and $35.48 \mathrm{~ms}$ (more than one pulse time but less than two pulses time). For three or more pulses that overlap, it is really rare and will not take effect on the statistical results, so we did not use them when counting. All the preprocessing methods were programmed with Matlab (Matlab 7.0, Mathworks), and after processing, the counting number of the three thresholds was used as the input layers to the BP neural network.

\section{Field sample test}

After the system was established, another 90 field samples were collected in the same location $\left(45^{\circ} 23^{\prime} \mathrm{N}, 129^{\circ}\right.$ $91^{\prime} \mathrm{E}, 133 \mathrm{~m}$ in altitude) to examine the system. When recording, the recorder was placed on a $0.3 \mathrm{~m}$ high tripod with a $0.5 \mathrm{~m}^{2}$ ranged marker in the grassland, with a wind shelter on the recorder's microphone; each sample took an hour and divided into six 10-min samples. After recording, the locust density were counted by eye to define the level; after that, all the samples were subjected to data preprocessing and input to the system, and the output results were compared with man-made counting, which meant that the man-made results were completely blindly obtained before they were input to the system. We just counted the final number of the locust within $0.5 \mathrm{~m}^{2}$ which does not include the in and out' insects during the recording time.

\section{Results}

\section{Song analysis}

The calling songs of Asian migratory locust have an obvious character of double pulses (Figure 3). For convenience, the first pulse was called pulse $\mathrm{A}$ and the other one was called pulse $B$, the former having higher amplitude and narrower width than the latter. Moreover, the intervals between pulse $\mathrm{A}$ and pulse $\mathrm{B}$ were stable, and so are the intervals between double pulses. The $\mathrm{S} / \mathrm{N}$ ratio (the ratio of signal/noise) is about 10 . By measuring 187 pulse groups of 16 individuals, we got a statistical result of song traits (Table 1 ). As listed in Table 1 , the $U$ test value of pulse amplitude and pulse width between pulse A and pulse B are very large, suggesting a significant difference. The relative errors of all traits were $1.7 \%$ to $6.3 \%$, reflecting a good stability. Therefore, the duration traits of pulses were used as parameters in our system.

\section{Data preprocessing results}

The counted results of the number of pulses in three different thresholds have been listed in Table 2, and each density resulted from 100 sound samples. The result

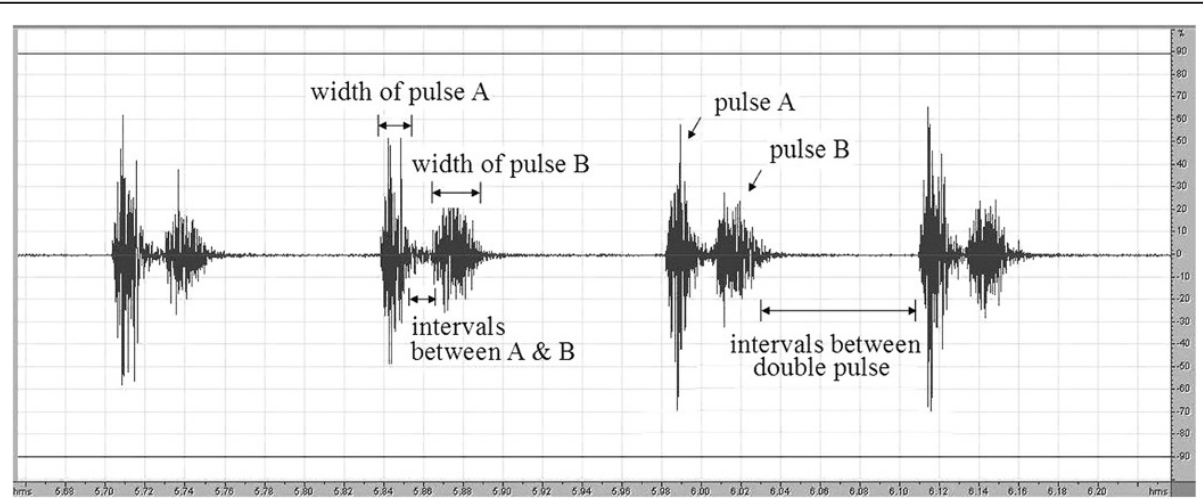

Figure 3 Time domain plot of L. migratoria migratoria calling songs. L. migratoria migratoria's songs showed obviously double pulses, with the stable duration time in pulse A and pulse B, the intervals between A and B, and also the intervals between pulse groups. 
Table 2 Count results of the number of pulse in three different thresholds after removing the bad data

\begin{tabular}{|c|c|c|c|c|}
\hline \multirow[t]{2}{*}{ Density (individuals $/ 0.5 \mathrm{~m}^{2}$ ) } & \multicolumn{4}{|c|}{ Pulse number $\left(\times 10^{3}\right)$} \\
\hline & Threshold 0.1 & Threshold 0.4 & & Threshold 0.7 \\
\hline 5 & & $1.060 \pm 0.048$ & $0.226 \pm 0.011$ & $0.0469 \pm 0.0028$ \\
\hline 25 & & $5.11 \pm 0.11$ & $1.380 \pm 0.023$ & $0.218 \pm 0.068$ \\
\hline 50 & & $10.26 \pm 0.29$ & $2.171 \pm 0.062$ & $0.416 \pm 0.014$ \\
\hline \multirow[t]{3}{*}{$U$ test value } & Between 5 and 25 & 337.0 & 357.6 & 25.1 \\
\hline & Between 25 and 50 & 166.1 & 156.3 & 28.6 \\
\hline & Between 5 and 50 & 312.9 & 309.0 & 258.7 \\
\hline
\end{tabular}

indicated that the pulse number in the same threshold was significantly different among the three densities. Taking the data as network input and the density levels of locust pest as network output, we established the classification system.

The effective number of pulses in three different thresholds is listed in Table 2. After removing noise, $U$ test showed that there is greatly significant differences in three densities, and when the threshold was over 0.7 , the number of pulses in three densities were $0.0469 \pm$ $0.0028,0.218 \pm 0.068$, and $0.416 \pm 0.014$, respectively, which is much less than the value of the threshold between 0.4 and 0.7 . It is suggested that when the density is high, the overlapping pulses are still very rare and take no big effect on the counting results, but, indeed, it was also increasing with the locust density. Half of the data were input to the BP neural network for training, and the rest were used as testing samples.

\section{Training results of neural networks}

For training neural networks, each density level randomly selected 15 samples from 30 samples, and the rest were the testing samples. Thus, the total number of training samples and testing samples was 45 . We trained neural networks 600 times, and the training target was 0.01 . Figure 4 shows the error curve of the network training. Table 3 shows the testing results of this BP neural network. As listed in Table 3, the correct rate of density level recognition reached $100 \%$, which showed that the system we established worked correctly in the laboratory environment.

\section{Field sample test}

After the system was established, field samples were used to test whether this system could be used in actual situations. After field recording, finally, we got 90 recording samples; thereinto, 34 samples were identified as low density, 23 were medium and 11 were high. The correct

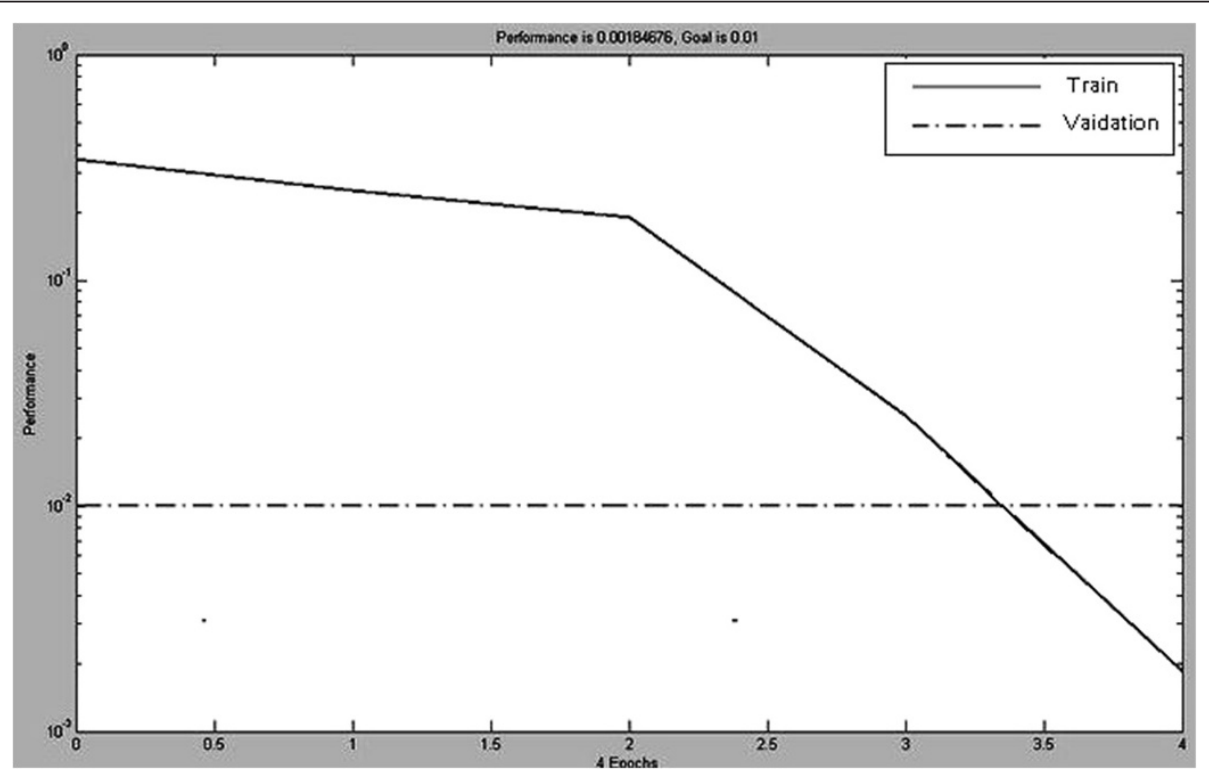

Figure 4 The error curve of neural network training. We trained neural networks 600 times; the training target was 0.01 , and the correct rate of density level recognition was 100\%. 
Table 3 Testing results of BP neural network

\begin{tabular}{llllll}
\hline & & $\begin{array}{l}\text { Testing } \\
\text { samples }\end{array}$ & Outputs & & \\
\cline { 4 - 6 } & & Density 1 & Density 2 & Density 3 \\
\hline Inputs & Density 1 & 15 & 15 & 0 & 0 \\
& Density 2 & 15 & 0 & 15 & 0 \\
\multicolumn{2}{c}{ Density 3 } & 15 & 0 & 0 & 15 \\
\multicolumn{2}{l}{ Correct number of output } & 15 & 15 & 15 \\
\hline
\end{tabular}

recognition rate of our system in field working environment is listed in Table 4. It is shown that the system also could be used in the field even if the rate is a little bit fewer than the BP neural network testing results.

\section{Discussion}

The calling songs of $L$. migratoria migratoria have an obvious character of double pulses which is not a rare phenomenon in Orthoptera insects (Greenfield 1990). The detailed study had been done in katydid Neoconocephalus affinis (Orthoptera: Tettigoniidae). The Fourier analysis of the stimulus envelopes revealed that females respond only when both the first and second harmonics of the AM spectrum are of similar amplitude. The second harmonic is generated by the amplitude difference between the two pulses making up a pulse pair. Females respond to double pulses that have been merged into a single pulse only if this amplitude modulation is preserved (Bush et al. 2009).

Insect songs had a good stability that is already used as a powerful tool in taxonomy, especially in some closerelated species (Schul 1998). Our result also suggested a stable acoustic trait in L. migratoria migratoria, which means that these methods could not only be used in $L$. migratoria migratoria but also in other acoustic insects such as katydids, crickets, and cicadas. Some studies showed that there was a differentiation of songs between geographically isolated populations (Heady and Denno 1991; Paillette et al. 1997). It is still not very clear for us whether there was a big differentiation of songs in $L$. migratoria migratoria; if so, we need to adjust the system to adapt to its changes in other locations, but it is convenient to just change some parameters.

Table 4 Field sample testing results of monitoring system

\begin{tabular}{lllll}
\hline & \multirow{2}{*}{$\begin{array}{l}\text { Testing } \\
\text { samples }\end{array}$} & \multicolumn{2}{l}{ Outputs } & \\
\cline { 5 - 5 } & & Low & Medium & High \\
\hline Inputs & & & & \\
Low & 34 & 34 & 0 & 0 \\
Medium & 23 & 0 & 21 & 2 \\
High & 11 & 1 & 0 & 10 \\
Correct rate of output & $100 \%$ & $91.30 \%$ & $90.91 \%$ \\
Total identified rate & $96.67 \%$ & & \\
\hline
\end{tabular}

There are several reasons why we choose the BP neural network as a statistical method: firstly, the calling songs of L. migratoria migratoria showed double pulses. Even if the calling time varied between different insects, the number of insects may not have a linear relationship with the number of pulses. Secondly, the number in three thresholds took different effects on the classification results. To avoid this, we just input the data in different thresholds and let the BP neural network train the system. The results showed that the BP neural network can provide accurate and effectual information in population density recognition.

There are some points worthy of notice for practical application. Firstly, the calling songs of L. migratoria migratoria were the symbol of sexual maturity, i.e., only adults could make songs by flapping the forewings. This system can accurately recognize the density level of locust plague, but not for the early monitoring. For several years of field observation and combined with the previous record of the local government, we obtained adult emergence time in the field of L. migratoria migratoria. August and September are the most proper time for our monitoring system because most of the adults appear in these two months in Northeast China. It is crucial to do so because the age of inspection is the major factor for us to determine when to use our system; moreover, a common application for density estimation is to determine whether a given population has increased or decreased significantly. Often density estimates between two time periods might be statistically significantly different; in our case, a single classification results cannot be used as a final conclusion. Comprehensive analysis was needed, that is to say, when monitoring a large area of the field, and the number of acoustic sensors and the time to record need to be considered.

\section{Conclusions}

Our results showed that the intraspecies acoustic characters could be used to identify the L. migratoria migratoria density based on the BP neural network and could be potentially used in other acoustic agriculture pest. In this paper, we just provided a theoretical method for the monitoring system which is a green, effective, and economical solution to automatically monitor the locust plagues and could be a potential guide to the manufacture of commercial monitoring system which is used in the field.

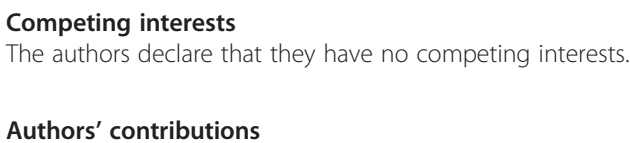

YW designed and carried out the experiments. XZ collected the insects and recorded the song samples in the lab and field. QH programmed the Matlab to analyze the samples and train the BP neural network. BR checked and 
commented on the manuscript. All authors read and approved the final manuscript.

\section{Acknowledgements}

This work is supported by the Special Fund for Agro-scientific Research on Public Interest (No. 200903021), Natural Science Foundation of China (No. 31172133), and the Fundamental Research Funds for the Central Universities (No. 11SSXT153). The system had been authorized for national patent of China (No. ZL201010518492.5). We are extremely grateful to John Cryan for the language correction (University College Cork, Cork, Ireland) and the members of our lab for the material collection. The materials used in this work are supported by the Central Lab, School of Life Sciences, Northeast Normal University, Changchun, China.

\section{Author details}

${ }^{1}$ Jilin Key Laboratory of Animal Resource Conservation and Utilization, School of Life Sciences, Northeast Normal University, Renmin St. 5268, Changchun 130024, China. ${ }^{2}$ School of Physics, Northeast Normal University, Renmin St. 5268, Changchun 130024, China.

Received: 4 May 2014 Accepted: 13 August 2014

Published: 22 August 2014

\section{References}

Bush SL, Beckers OM, Schul J (2009) A complex mechanism of call recognition in the katydid Neoconocephalus affinis (Orthoptera: Tettigoniidae). J Exp Biol 212:648-655

Ceccato P, Bell MA, Blumenthal MB, Connor SJ, Dinku T, Grover-Kopec EK, Ropelewski CF, Thomson MC (2006) Use of remote sensing for monitoring climate variability for integrated early warning systems: applications for human diseases and desert locust management. Paper presented at the geoscience and remote sensing symposium. Columbia University, NewYork

Drake VA, Wang HK, Harman IT (2002) Insect monitoring radar: remote and network operation. Comput Electron Agr 35:77-94

Ewing AW (1989) Arthropod bioacoustic. In: Neurobiology behaviour. Comstock Publishing Associates, New York

Fischer FP, Schulz U, Schubert H, Knapp P, Schmöger M (1997) Quantitative assessment of grassland quality: acoustic determination of population sizes of orthopteran indicator species. Eco Soc America 7:909-920

García MD, Lorier E, Clemente E, Presa JJ (2003) Sound production in Parapellopedon instabilis (Rehn, 1906) (Orthoptera: Gomphocerinae). Annales de la Socie'te entomologique de France (NS) 39:335-342

Greenfield MD (1990) Evolution of acoustic communication in the genus Neoconocephalus: discontinuous songs, synchrony, and heterospecific interactions. In: Bailey WJ, Rentz DCF (eds) The Tettigoniidae: biology, systematics and evolution. Springer, Heidelberg, pp 71-97

Heady SE, Denno RF (1991) Reproductive isolation in Prokelisia planthoppers (Homoptera: Delphacidae): Acoustic differentiation and hybridization failure. J Insect Conserv 4:367-390

Hemp C, Kehl S (2010) Taxonomic changes and new species of the flightless genus Parepistaurus Karsch, 1896 (Orthoptera: Acrididae, Coptacridinae) from mountainous East Africa. J Orthop Res 19:31-39

López H, García MD, Clemente E, Presa JJ, Oromí P (2007) Sound production mechanism in pamphagid grasshoppers (Orthoptera). J Zool 275:1-8

Ma J, Han X, Hasibagan A, Wang C, Zhang Y, Tang J, Xie Z, Deveson T (2005) Monitoring East Asian migratory locust plagues using remote sensing data and field investigations. Int J Remote Sens 26:629-634

Montealegre-Z F, Morris GK (2004) The spiny devil katydids, Panacanthus Walker (Orthoptera: Tettigoniidae): an evolutionary study of acoustic behaviour and morphological traits. Syst Entomol 29:21-57

Ngo BV, Ngo CD (2013) Reproductive activity and advertisement calls of the Asian common toad Duttaphrynus melanostictus (Amphibia, Anura, Bufonidae) from Bach Ma National Park, Vietnam. Zoological Studies 52:12

Pace F, Benard F, Glotin H, Adam O, White P (2010) Subunit definition and analysis for humpback whale call classification. Appl Acoust 71:1107-1112

Paillette M, Bizat N, Joly D (1997) Differentiation of dialects and courtship strategies in allopatric populations of Drosophila teissieri. J Insect Physiol 43:809-814

Parkman JP, Frank JH, Walker TJ, Schuster DJ (1996) Classical biological control of Scapteriscus spp. (Orthoptera: Gryllotalpidae) in Florida. Environ Entomol $25: 1415-1420$
Ragge DR, Reynolds WJ (1998) The songs of the grasshoppers and crickets of Western Europe. Harley Books, Colchester

Riede K (1998) Acoustic monitoring of Orthoptera and its potential for conservation. J Insect Conserv 2:217-223

Schmidt GH, Stelzer R (2005) Characterization of male structures, and the stridulatory organs of Pantecphylus cerambycinus (Ensifera: Tettigonioidea: Pseudophyllidae). Entomol Gen 27:143-154

Schul J (1998) Song recognition by temporal cues in a group of closely related bushcricket species (genus Tettigonia). J Comp Physiol A 183:401-410

Shi RX, Liu C, Li D-M, Xie B-Y (2003) Application of MODIS_NDVI to monitoring locust pest in Baiyang Shallow Lake. J Nutr Dis 12:155-160

Uvarov B (1996) Grasshoppers and locusts: a handbook of general acridology, vol 1. Cambridge University Press, London, $\mathrm{p} 8$

von Helversen D (1972) Gesang des MSnnchens und Lautschema des Weibchens bei der Feldheuschrecke Chorthippus biguttulus L. J Comp Physiol A 81:381422

Wang Y, Zhang J, Li X, Ren B (2011) Acoustic and molecular differentiation between macropters and brachypters of Eobiana engelhardti engelhardti (Orthoptera: Tettigonioidea). Zoological Studies 50(5):636-644

Zhang DX, Yan L-N, Ji Y-J, Hewitt GM, Huang Z-S (2009) Unexpected relationships of substructured populations in Chinese Locusta migratoria. BMC Evol Biol 9:144

doi:10.1186/s40555-014-0055-x

Cite this article as: Wang et al:: Application of insect songs in monitoring population density level of Locusta migratoria migratoria (Orthoptera: Acrididae). Zoological Studies 2014 53:55.

\section{Submit your manuscript to a SpringerOpen ${ }^{\odot}$ journal and benefit from:}

- Convenient online submission

- Rigorous peer review

- Immediate publication on acceptance

- Open access: articles freely available online

- High visibility within the field

- Retaining the copyright to your article

Submit your next manuscript at $>$ springeropen.com 